\title{
Analysis of Foundation Pit Design of Metro Station in Complex Environment
}

\author{
Yunchao Tao \\ Urban Rail Transit Engineering Company Limited of China Railway 15th Bureau, Luoyang 47100, China \\ Correspondence should be addressed to Yunchao Tao; taoyunchaocr15g@163.com
}

Received 19 June 2021; Revised 27 October 2021; Accepted 29 October 2021; Published 2 December 2021

Academic Editor: Wei Liu

Copyright (c) 2021 Yunchao Tao. This is an open access article distributed under the Creative Commons Attribution License, which permits unrestricted use, distribution, and reproduction in any medium, provided the original work is properly cited.

\begin{abstract}
The complex engineering geological conditions and the surrounding environmental conditions of the existing subway lines and adjacent buildings have significantly deepened the difficulty of metro station foundation pit design and construction. Based on the foundation pit project of Luboyuan Station of Nanjing Metro Line 9, this study chooses a reasonable foundation pit support design scheme to carry out related research by analyzing the site geological environmental conditions. Through the analysis and evaluation of the engineering geological conditions of the engineering site, the engineering geological problems that may occur in the process of construction are given. According to the lithologic characteristics of the site strata, the hydrogeological conditions, and the features of the underground engineering structure, the design of the foundation pit supporting system is optimized and analyzed. The results show that making full use of the geological features of strata and adopting effective support methods can ensure the safety of foundation pit construction, reduce the cost of engineering description, and shorten the construction period, which can be used as a reference for similar projects and construction.
\end{abstract}

\section{Introduction}

With the high development of urbanization, the high concentration of population, and the rapid growth of motor vehicle ownership, the phenomenon of urban traffic congestion is becoming more and more serious. At present, traffic carrying capacity is a binding condition for urban development [1-4]. Rail transit has the advantages of convenience, high speed, and enormous power and has become an essential part of the urban modern, high-quality, comprehensive three-dimensional traffic network. It can greatly improve the problem of urban traffic congestion [5-7]. At the same time, the new development concept under the traffic-guided development (TOD, transit-oriented development) mode, rail transit led the urban development pattern, has undergone new changes, not only to reshape the urban space form, but also to change the urban planning and market space [8]. Therefore, the transportation department has been promoting the high-speed and high-quality development of urban rail transit.
By 2020, 10 subway lines have been opened in Nanjing, including Line 1 to Line 4, Line 10, Line S1, Line S3, and Line S7 to Line S9, forming a subway network covering 11 municipal districts in Nanjing $[9,10]$. As shown in Figure 1, the operating mileage of $378 \mathrm{~km}$ ranks sixth in the country, and Nanjing has become the first city in China to open subways in all districts and counties, sharing $53.82 \%$ of the city's public transport. However, because Nanjing straddles the Yangtze River, three bedrock uplifts, and two sag basins in the central city, the Qinhuai River runs through from south to north [11]. According to the division of main engineering geological zones and distinct soil layers in the Nanjing area, Hongzhong Xu, and others, the engineering geological conditions are mainly classified as the floodplain of the Yangtze River (distributed primarily on the banded area with a certain width on both sides of the Yangtze River), the ancient channel of the Qinhuai River, and multistage river terraces, and the soil layer parameters are pretty different from each other [12]. Zheng et al. [13] believe that there are three types of geomorphological units 


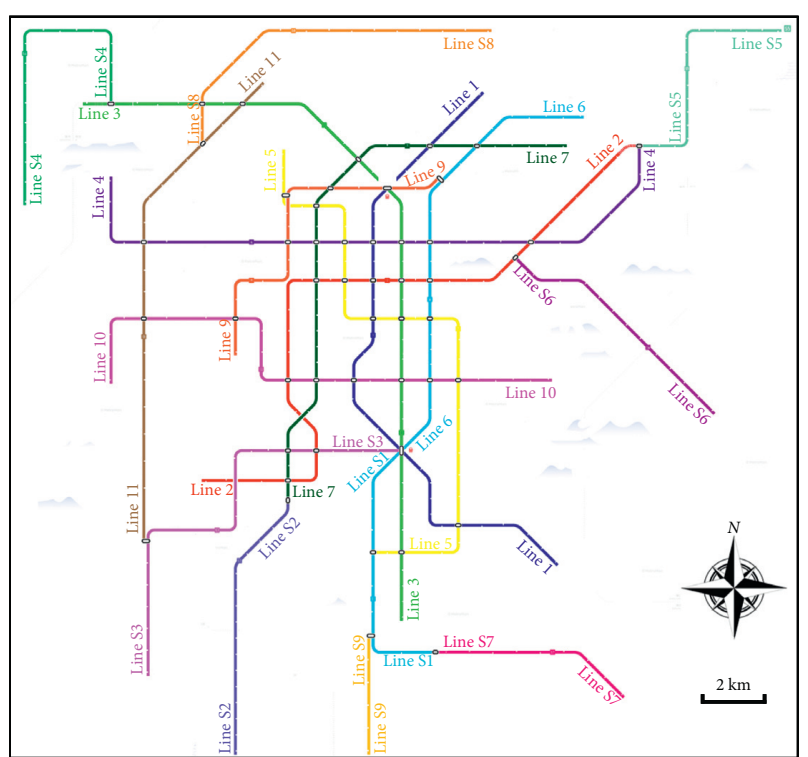

Figure 1: Planning map of Nanjing Metro Line from 2019 to 2023.

in the Nanjing area: tectonic denudation low mountain and hilly area, inter-hillock depression area, and river valley plain area, with various engineering geological and hydrogeological conditions, and the subway tunnel is a linear project passing through different geomorphological units. The engineering geological and hydrogeological properties of each team are very different. Nanjing's complex engineering geological conditions and the surrounding environmental conditions of existing subway lines and adjacent buildings have considerably deepened the difficulty of design and construction. At present, the new mileage of the Nanjing subway is slower than that of other provincial capitals.

The shallow layer in the Nanjing area mostly belongs to the water-rich soft soil foundation, and the shield construction is usually used to dig the subway tunnel. The open excavation method is used to carry out the station construction [14-17]. The open-cut subway station needs to build the foundation pit retaining structure first and then excavate the bottomless foundation pit [18-20]. However, the subway station is generally located in the bustling area of the city, with a concentrated population, dense buildings, and many underground pipelines $[21,22]$. The excavation of the bottomless foundation pit of the station can easily lead to the displacement of the surrounding soil and land subsidence. The support design and construction of the foundation pit should be considered to bring great risks to the surrounding environment $[23,24]$. In recent years, in the construction of deep foundation pit engineering in the Jiangsu and Zhejiang areas, major engineering accidents have been caused due to complex site engineering geological conditions, complex surrounding environmental conditions, and improper selection of supporting structures, resulting in a large number of economic losses. A diaphragm wall is widely used as the retaining structure of a deep foundation pit because of its slight vibration, high stiffness, and good anti-seepage.
Of the 760 subway stations built along the southeast coast in the past 20 years, 650 have adopted diaphragm walls as foundation pit retaining structures. Taking the deep foundation pits of 48 subway stations collected in Nanjing, for example, only 21 foundation pits are protected by underground diaphragm walls, bored piles cover another 26, and one project uses SMW piles [25,26]. Most of the projects that select diaphragm walls as bottomless foundation pit retaining structures are located in the floodplain of the Yangtze River and the ancient channel of the Qinhuai River. A bored cast-in-place pile is often used in the retaining design of a deep foundation pit under the condition of a river terrace. Therefore, although some technical standards and specifications can guide local subway construction, the construction experience of similar projects still needs to be used as a reference in the actual design.

However, the difference in physical and mechanical properties of regional soil layer cannot be blindly copied. It may cause unnecessary waste to blindly select the support mode without sufficient consideration, or unilaterally improve the safety factor of support. It is imperative to make rational use of the geological structure characteristics of rock and soil and the surrounding environmental conditions to reduce the project cost-effectively, solve the technical problems of foundation pit construction, and speed up the construction speed and other factors [27, 28].

In this study, taking the foundation pit design of Luboyuan Station in the fourth project of Nanjing Metro Line 9 as an example, through the analysis and evaluation of the engineering geological conditions of the project site, this study gives the engineering geological problems that may occur in the process of construction. According to the onsite lithologic characteristics of strata, the hydrogeological conditions, and the structural elements of underground engineering, the design of the foundation pit supporting structure is optimized and analyzed.

\section{General Situation of the Project}

2.1. Project Overview. The first phase of Line 9 is a local line in the northwest direction of the network, starting from Danxia Road Station in the north and Binjiang Park Station in the south, passing through three administrative districts: Xuanwu District, Gulou District, and Jianyu District. The total length of the line is $19.68 \mathrm{~km}$, all underground lines, with a total of 16 stations, including 9 transfer stations, with an average station spacing of $1.26 \mathrm{~km}$ (see Figure 2).

The Luboyuan Station of this project is an underground three-story island platform station with a double-column three-span box frame structure. The open-cut method is adopted for construction. The station hall is on the first underground floor, the equipment is on the second underground floor, and the platform is on the third underground floor (see Figure 3).

2.2. Surrounding Environment. The main underground pipelines affecting the construction of the main enclosure structure of Luboyuan Station are as follows: buried $4.6 \mathrm{~m}$ 


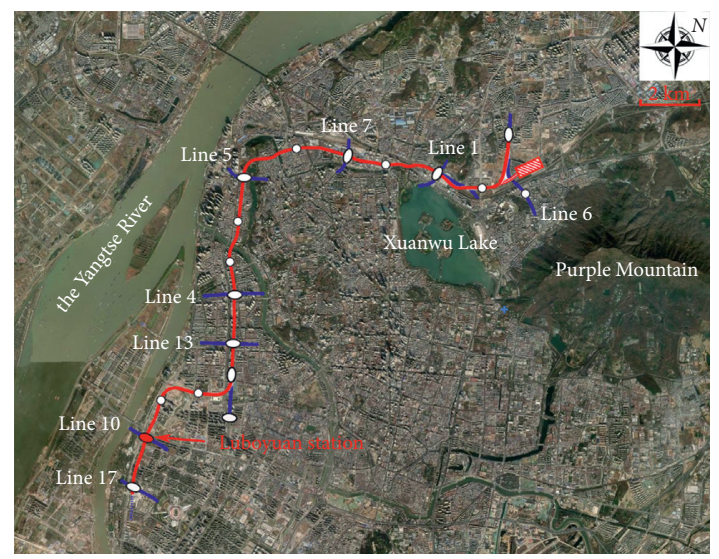

Figure 2: General plan of the first-phase project of Nanjing Metro Line 9.

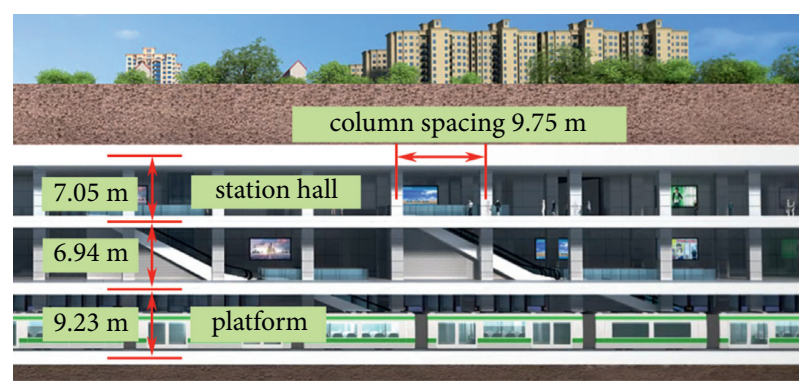

Figure 3: Luboyuan Station profile based on BIM technology.

$220 \mathrm{kV}$ power pipe, buried deep $1.2 \mathrm{~m} 380 \mathrm{~V}$ power pipe, buried deep $2.85 \mathrm{~m} \mathrm{DN800} \mathrm{rain} \mathrm{pipe,} \mathrm{and} \mathrm{buried} 4.6 \mathrm{~m}$ communication optical cable. The main underground pipelines affecting the construction of the auxiliary enclosure structure of Luboyuan Station are as follows: buried $4.6 \mathrm{~m} 220 \mathrm{kV}$ power pipe, buried $2.85 \mathrm{~m} \mathrm{DN800} \mathrm{rain} \mathrm{pipe,}$ buried $2.85 \mathrm{~m}$ DN400 rain pipe, and buried $1.2 \mathrm{~m}$ DN1400 water supply pipe. Ground green water pipes, street lamp power lines, signal light communication lines, and other small scattered pipelines in the site shall be abolished on the spot.

The northwest side of the station is Nanjing China Greening Expo Park, the southwest side is Yuanjiang Fishing Port, and the southeast and northeast sides are green open spaces (see Figure 4). The adjacent buildings also include the Luboyuan Station of Line 10 (underground second-floor station, T-type transfer) and the underground comprehensive pipe corridor of the Yangtze River Rapid Avenue Reconstruction Project (underground first floor, about $7 \mathrm{~m}$ from the main body of the station).

2.3. Geology and Hydrology. The landform of Luboyuan Station belongs to the geomorphological unit of Ningzhen Yangqiu hills and plain area and river valley plain. The site is distributed on the south side of the Yangtze River, and the terrain is flat and open. The station is arranged along the Yangtze River Avenue, which is about $82 \mathrm{~m}$ wide. The ground along the line is relatively flat, and the present

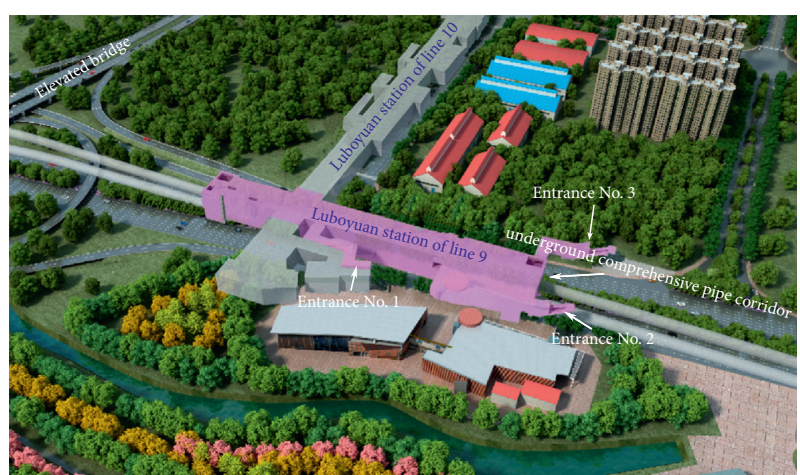

FIgURE 4: Surroundings of the station.

ground elevation is between $5.1 \mathrm{~m}$ and $5.7 \mathrm{~m}$. The near surface mainly consists of Holocene (Q4) artificial filling, silty clay, and muddy silty clay (mixed with silt and silt). The groundwater in this site is mainly pore phreatic water, and due to the great difference in permeability between the weak clayey soil layer in the upper and middle and lower parts of the site and the sandy soil and gravel-bearing silty clay at the bottom, the groundwater in sandy soil layer and gravelbearing silty clay has micro-pressure-bearing property. In addition, there is a small amount of bedrock fissure water in the bedrock weathering zone.

\section{Analysis of Engineering Geological Conditions}

3.1. Division of Engineering Geological Strata. To find out in detail the regional geological, hydrogeological, and engineering geological conditions of the site area, the suitability of foundation types and construction methods is analyzed and evaluated, the possible geotechnical problems are predicted, and a large number of field and laboratory tests are carried out. According to the geological survey and survey data combined with the geomorphological unit, the geomorphological type of this site belongs to the geomorphology of the Yangtze River floodplain, and the engineering geological division belongs to the Yangtze River floodplain engineering geological area (subarea). The artificial filling is widely distributed on the surface of the field area, followed by clay, silty clay, muddy silty clay (mixed with silt and silty sand), silty clay (mixed with silt and silty sand), silty sand, medium-coarse sand, and gravel. The underlying bedrock is the sandy mudstone of the Cretaceous Pukou Formation. The rock surface does not fluctuate much, and the burial depth is about $50 \mathrm{~m}$ to $53 \mathrm{~m}$. The rock and soil in the site are divided into 16 layers by engineering geological. This layered scheme has many quantities and complex contents, which is not conducive to the use of designers. In this study, according to the age, genesis, state characteristics, and buried depth of rock and soil layer, the strata in the excavation depth of the foundation pit are divided into 6 layers, as shown in Figure 5 and Table 1.

The exploration holes in this survey are mainly arranged in a " $Z$ " shape crossing $3 \sim 5 \mathrm{~m}$ outside the outline of the main structure, and the interval of the exploration holes is about 


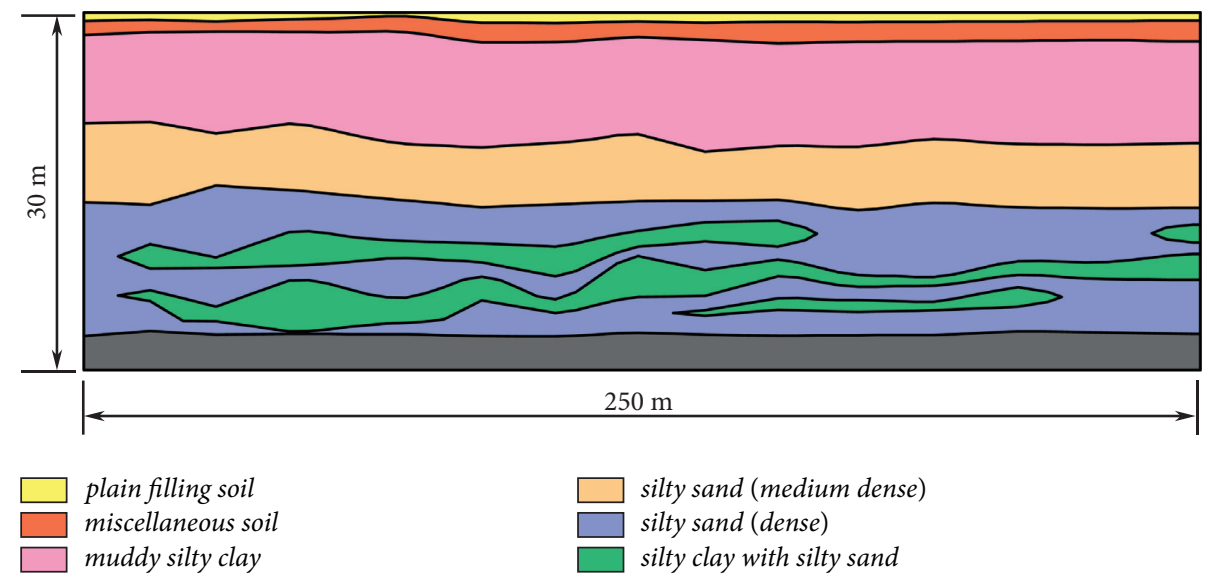

Figure 5: Longitudinal geological profile of Luboyuan Station.

TABLE 1: A list of stratigraphic distribution in Luboyuan Station.

\begin{tabular}{|c|c|c|c|}
\hline $\begin{array}{l}\text { The cause of } \\
\text { the times }\end{array}$ & Stratum name & Feature & Thickness (m) \\
\hline \multirow[t]{2}{*}{$\mathrm{Q}_{4}^{\mathrm{ml}}$} & Miscellaneous soil & $\begin{array}{c}\text { Miscellaneous colors, mainly grayish-yellow and gray; loose to slightly dense; } \\
\text { mainly composed of construction waste, containing a large number of bricks, } \\
\text { stones, concrete blocks, and a small amount of silty clay; the surface is partially } \\
\text { concrete floor }\end{array}$ & $1.00 \sim 4.10$ \\
\hline & Plain filling soil & $\begin{array}{l}\text { Grayish-yellow, grayish-brown; loose to slightly dense; mainly composed of clayey } \\
\text { soil, see shells and screw fragments, mixed lime, and a small amount of macadam }\end{array}$ & $0.60 \sim 2.20$ \\
\hline \multirow{4}{*}{$\mathrm{Q}_{4}{ }^{\mathrm{al}+1}$} & Muddy silty clay & $\begin{array}{l}\text { Gray, grayish-brown; flow plastic; soil quality is uneven, with horizontal bedding, } \\
\text { sandwiched with silt and a thin layer of silty sand, showing thousands of layers of } \\
\text { cake; the middle and lower part of the sand content is gradually higher, with high } \\
\text { pressure, occasionally see shell fragments and rotten plants }\end{array}$ & $0.80 \sim 22.40$ \\
\hline & $\begin{array}{l}\text { Silty sand (medium } \\
\text { dense) }\end{array}$ & $\begin{array}{l}\text { Gray, bluish-gray; medium dense; poor gradation; mineral composition is mainly } \\
\text { quartz, feldspar, see mica debris, local sandwiched with a thin layer of silty clay }\end{array}$ & $1.80 \sim 15.00$ \\
\hline & Silty sand (dense) & $\begin{array}{l}\text { Gray, bluish-gray; dense; poor gradation; mineral composition is mainly quartz, } \\
\text { feldspar, see mica debris, local sandwiched with a thin layer of silty clay }\end{array}$ & $1.30 \sim 17.40$ \\
\hline & $\begin{array}{l}\text { Silty clay with silty } \\
\text { sand }\end{array}$ & $\begin{array}{l}\text { Grayish brown; soft plastic; soil quality is uneven, with horizontal bedding; the } \\
\text { thickness of the single layer is about } 5 \mathrm{~mm} \text { to } 20 \mathrm{~m} \text {, the thickness of the single layer } \\
\text { is about } 2 \sim 5 \mathrm{~mm} \text { silt and silty sand, and the thickness ratio is about } 4: 1\end{array}$ & $0.90 \sim 3.1$ \\
\hline
\end{tabular}

$20 \mathrm{~m}$. The exploration holes on the inner side of the station structure are added, with the hole spacing not greater than $24 \mathrm{~m}$. A total of 50 exploration holes are arranged, including 16 control holes, 34 general holes, and 11 test holes.

The physical and mechanical properties of the rock and soil mass of the site are shown in Figure 6 and Table 2. It can be seen from the table that the upper soil has low strength, general compressibility, pore ratio and permeability, poor uniformity, and poor engineering geological performance, and belongs to aquitard. It is a weakly permeable layer. The central soil has low strength, high compressibility, extremely poor engineering geological performance, and uneven permeability. The permeability in the horizontal direction is significantly greater than that in the vertical direction, belonging to the weak permeable layer. The lower part has general strength, low compressibility, and general engineering geological performance and belongs to the medium permeable layer. The bottom soil has low strength, medium and high compressibility, and poor engineering geological performance. Due to the inclusion of a large amount of silt, the permeability in the horizontal direction is obviously greater than that in the vertical direction, which is a weakly permeable layer.

\subsection{Evaluation of Engineering Stability and Main Problems.} The depth of the foundation pit of the main body of the station is about $26.20 \mathrm{~m}$, the depth of the foundation pit of the ancillary structure (entrance, air shaft, etc.) is about $12.10 \mathrm{~m}$, and the buried depth is large; there are no buildings in the upper part, and the groundwater level is high. The main basement of the station is located in the lower soil, and the engineering geological performance of this layer is general; the substrates of ancillary structures are all located in the middle soil, muddy silty clay, and silty sand, and this layer is a soft soil layer, which is easy to produce an uneven settlement, so the comprehensive evaluation of the stability of the foundation is insufficient. 

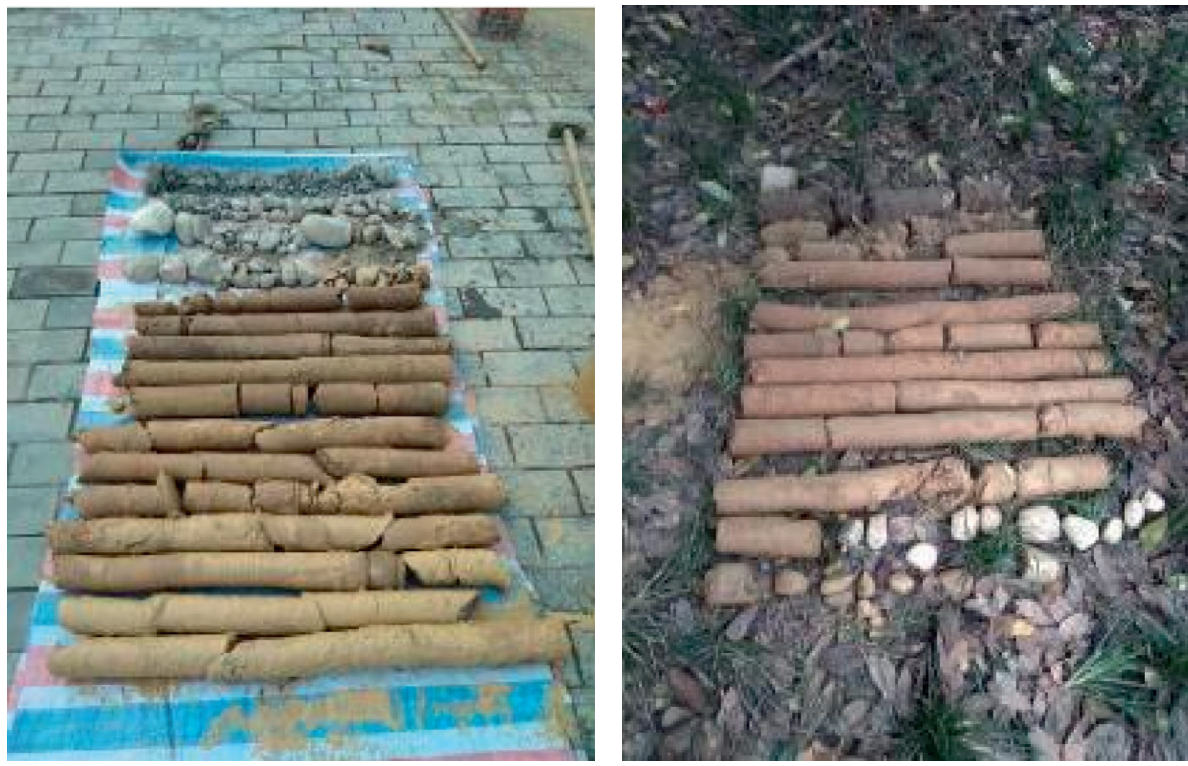

FIGURE 6: Borehole samples.

TABLe 2: Physical and mechanical property index of stratum soil in Luboyuan Station.

\begin{tabular}{|c|c|c|c|c|c|c|c|c|}
\hline Stratum name & $\begin{array}{c}\text { Water } \\
\text { content } \\
(\%)\end{array}$ & $\begin{array}{l}\text { Density } \\
\left(\mathrm{g} / \mathrm{cm}^{3}\right)\end{array}$ & $\begin{array}{l}\text { Void } \\
\text { ratio }\end{array}$ & $\begin{array}{l}\text { Liquidity } \\
\text { index }\end{array}$ & $\begin{array}{l}\text { Compression } \\
\text { modulus (MPa) }\end{array}$ & $\begin{array}{l}\text { Cohesion } \\
\quad(\mathrm{kPa})\end{array}$ & $\begin{array}{c}\text { Internal } \\
\text { friction angle } \\
\left({ }^{\circ}\right)\end{array}$ & $\begin{array}{c}\text { Permeability } \\
\text { coefficient }(\mathrm{cm} / \mathrm{s})\end{array}$ \\
\hline Miscellaneous soil & 31.9 & 1.93 & 0.867 & 0.54 & 5.84 & - & - & - \\
\hline Plain filling soil & 31.9 & 1.91 & 0.892 & 0.59 & 4.18 & - & - & $0.14 \times 10^{-6}$ \\
\hline $\begin{array}{l}\text { Muddy silty clay } \\
\text { (with microscale } \\
\text { sand) }\end{array}$ & 39.2 & 1.80 & 1.105 & 1.22 & 3.36 & 14.4 & 15.9 & $0.87 \times 10^{-6}$ \\
\hline Silty sand & 23.2 & 1.94 & 0.703 & - & 13.18 & 2.9 & 31.4 & $1.76 \times 10^{-3}$ \\
\hline Silty sand & 26.9 & 1.88 & 0.810 & - & 11.11 & 2.8 & 31.0 & $1.30 \times 10^{-3}$ \\
\hline $\begin{array}{l}\text { Silty clay with silty } \\
\text { sand }\end{array}$ & 32.0 & 1.83 & 0.962 & 0.96 & 3.94 & 17.2 & 20.4 & $1.38 \times 10^{-6}$ \\
\hline
\end{tabular}

Considering that the foundation pit of the station is close to the buildings under construction and municipal roads, there are many underground pipelines, and the surrounding environment is more complex. In the excavation depth, the soil is extremely loose, and the soil structure and self-stability are poor; it is easy to be disturbed and collapse, and lateral displacement deformation occurs. The main problems of foundation pit construction are slope instability, pit bottom uplift, piping, quicksand, and surrounding buildings, roads, underground pipelines, and facilities. Combined with the geological conditions, the hydrological conditions, and the excavation depth of foundation pit and surrounding environment, the main retaining structure of the project adopts diaphragm wall + internal support, the maintenance structure of ancillary structure adopts soil mixing wall (SMW) pile + internal support, and the internal clearance can be supported by concrete and steel. The support system should not only meet the requirements of bearing capacity but also meet the requirements of deformation.

\section{Foundation Pit Engineering Design}

4.1. Underground Diaphragm Wall Design. The original ground elevation of the station is $5.18 \mathrm{~m}$ to $5.78 \mathrm{~m}$, the enclosure structure is $1200 \mathrm{~mm}$ thick underground diaphragm wall, the inner and outer sides of the diaphragm wall are reinforced by $\Phi 850 @ 600$ triaxial mixing piles (Figure 7), and the reinforcement depth is $20 \mathrm{~m}$. Strongly weathered sandy mudstone (waterproof layer) is inserted into the bottom of the diaphragm wall to form a closed foundation pit to cut off underground diving and micro-confined water supply. The pipe well is used to drain in the hole, the groundwater level is lowered to $1 \mathrm{~m}$ below the excavation surface of the foundation pit, and observation wells are arranged outside the pit, which can be used as recharge wells if necessary. The foundation pit supporting the structure of Luboyuan Station adopts $1200 \mathrm{~mm}$ thick diaphragm wall, a total of 84 pieces, and $\mathrm{H}$-shaped steel joints; the average length of the wall is $54 \mathrm{~m}$, and the toe of the wall is located in the strongly weathered sandy mudstone layer. C35 underwater concrete is adopted for underground diaphragm wall, 


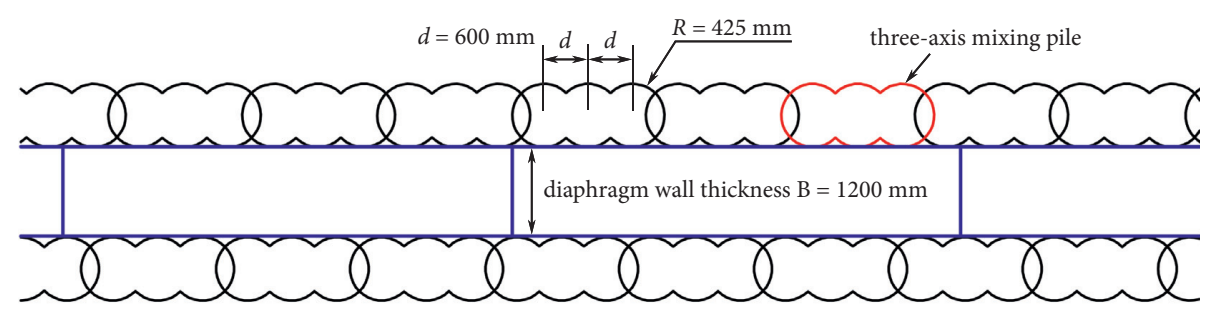

FIgURE 7: Schematic diagram of groove wall reinforcement.

with the compressive strength of $16.7 \mathrm{MPa}$ and an elastic modulus of $31500 \mathrm{MPa}$, and the concrete impermeability grade is not less than P6.

4.2. Support System Design. The standard section of the central foundation pit is provided with seven braces along with the depth of the foundation pit. The first and fifth are reinforced concrete braces, the second, third, and fourth are steel braces of $\Phi 609$, and the sixth and seventh are steel braces of $\Phi 800$. The support arrangement of the east-west end well is the same as the standard section except that the distance between the vertical layouts of the support is different. The horizontal spacing of the first concrete support is about $9 \mathrm{~m}$, and a closed reinforced concrete ring beam is arranged at the top of the ground diaphragm wall, and the concrete ring beam is used as the girder of the first support and the anti-floating top beam of the main structure at the same time. The horizontal spacing of the second, third, fourth, fifth, sixth, and seventh supports is $3 \mathrm{~m}$. The steel plate at the end of the support is embedded in the ground diaphragm wall, and the steel support acts directly on the ground wall without setting a steel girder. There is a row of $460 \mathrm{~mm} \times 460 \mathrm{~mm}$ temporary lattice columns in the middle, and the lattice foundation adopts " 850 bored cast-in-place piles." The ancillary structure of the station is an underground single-story structure, and the excavation depth of the foundation pit is $9.5 \mathrm{~m}$ to $9.8 \mathrm{~m}$. The enclosure structure adopts 8550@600SMW construction method pile + internal support system (2 vertical braces, the first is a concrete brace and the second is steel bracing), and $\Phi 700 @ 500$ biaxial mixing piles reinforce the bottom of the pit. The reinforced concrete inner support can give full play to the characteristics of high compressive bearing capacity, small deformation, and significant stiffness of the substantial material, which plays an important role in reducing the horizontal displacement of the enclosure and ensuring the overall stability of the enclosure, and reduces the cost of technical construction measures at the same time, as shown in Figure 8. C35 concrete is adopted for reinforced concrete inner support, with compressive strength of $11.9 \mathrm{MPa}$ and elastic modulus of $28000 \mathrm{MPa}$.

4.3. Soil Excavation Design. The primary foundation pit of Luboyuan Station is divided into two small foundation pits due to the transfer of Line 10 . The $160 \mathrm{~m}$ small foundation pit at the south end uses step excavation to carry out earthwork (see Figure 9). The excavation direction is carried

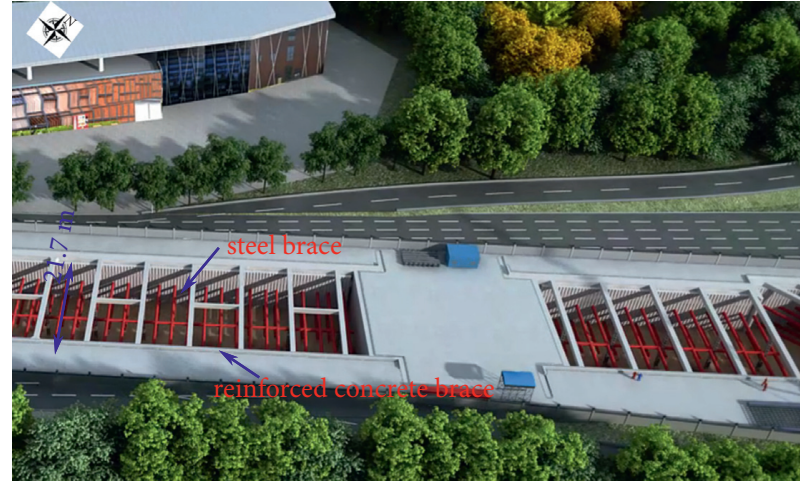

Figure 8: BIM schematic diagram of support system.

out from south to north (to ensure the shield receiving site). Finally, the remaining earthwork collection, vertical transportation, centralized accumulation, and outward transportation are carried out near the transfer node. The $55 \mathrm{~m}$ small foundation pit at the north end is carried out earthwork by vertical excavation; according to the working condition of the enclosure, the site in the northwest corner of the foundation pit is relatively spacious, and the vertical transportation operation point and temporary Earth accumulation area can be set up; the Earth is transported vertically by clam grab or car hoist, and the excavator in the foundation pit cooperates to collect the earthwork to the northwest corner; the distance between steel supports is optimized, and the hoisting shaft of excavator is set up.

4.4. Main Technical Difficulties and Measures. The construction of foundation pit excavation, dewatering, and structure will cause a disturbance, uneven settlement, and noise pollution and hinder the regular operation of the existing line, and the requirements of production management and control are high because of the transfer between the Luboyuan Station and the current Line 10; foundation pit excavation, dewatering, structure, and other construction will affect the existing line. When the underground diaphragm wall passes through the silt and silty sand layer, it is straightforward to cause defects such as collapse, mud entrainment, and hole, and it is difficult to form a groove; it is straightforward to cause defects such as limit invasion, displacement, and forking, and it is challenging to control verticality; it is easy to cause defects such as joint winding and leakage, and common handling is complex. Located in the floodplain stratum of the Yangtze River, it is not easy to control the effect of dewatering. Too heavy 


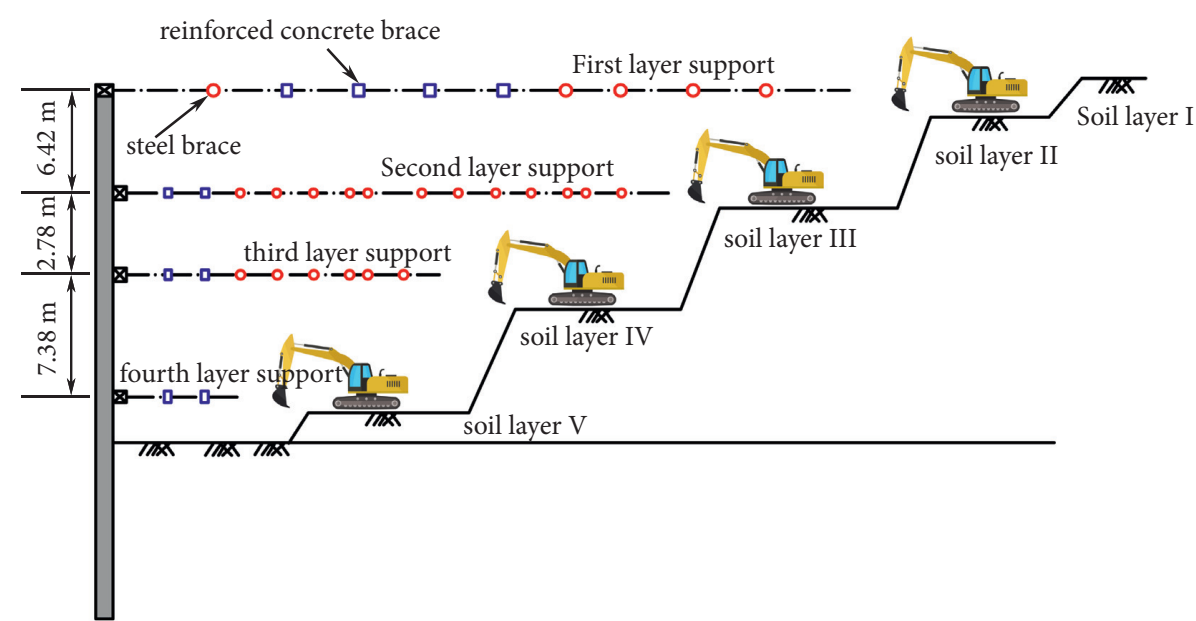

FIGURE 9: Profile of earthwork excavation.

precipitation is easy to cause land subsidence, settlement, and cracking of surrounding structures, too easy-to-cause foundation pit water level cannot go down, and excavation is difficult.

To ensure the safety of the existing line, the quality control of the joints of the diaphragm wall, and the effect of foundation pit excavation and dewatering, it has been worked out that if the necessary joint treatment of the enclosure structure is done well, the slotting machine is used to chisel off part of the concrete of the old diaphragm wall to ensure the integrity of the concrete structure. In the process of grooving construction of the underground wall, we should focus on controlling the verticality of the grooving and strengthening the training of the technical level of the grooving driver to ensure that the verticality of each underground wall meets the requirements of $0.3 \%$ of the code. After each underground continuous wallis grooved, the perpendicularity must be detected by ultrasonic detector. The construction of the lower groove wall from the verticality ultrasonic testing data is adjusted timely; the monitoring and analysis of the water level and water quantity in the dewatering operation are strengthened, the problems found in time are dealt timely, and the number of pumping wells and pumping flow, and dewatering as needed are adjusted, to ensure the safety of foundation pit and environment and other detailed construction plan measures.

\section{Results and Analysis}

The foundation pit design scheme proposed in this study is used for construction. At the same time, the wall settlement of underground diaphragm wall, wall deformation of diaphragm wall, reinforcement internal force of diaphragm wall, surface settlement around the station, and axial force of steel support are monitored. The monitoring data are processed and analyzed, and the results are summarized as follows:

(1) The maximum settlement rate of diaphragm wall is $0.02 \mathrm{~mm} / \mathrm{d}$, the maximum monthly settlement is $0.65 \mathrm{~mm}$, and the maximum cumulative settlement is $9.25 \mathrm{~mm}$.
(2) The inclination of the diaphragm wall of the foundation pit is monitored. The maximum monthly inclination value is $1.5 \mathrm{~mm}$, and the cumulative maximum deviation is $8.6 \mathrm{~mm}$ (the warning value is $25 \mathrm{~mm})$.

(3) The reinforcement internal force of the diaphragm wall is monitored. The maximum stress of the reinforcement is $15.7 \mathrm{kN}$, which is located $18.6 \mathrm{~m}$ below the top surface of the diaphragm wall.

(4) The surface settlement around the station is monitored. The maximum monthly settlement is $1.3 \mathrm{~mm}$, and the maximum cumulative settlement is $9.1 \mathrm{~mm}$.

(5) The maximum axial force of steel brace is $1564 \mathrm{kN}$, and the axial force of single steel pipe brace does not exceed its ultimate stability bearing capacity.

According to the above analysis, based on the foundation pit deformation control standard in Nanjing, the results show that the bearing capacity and deformation of the supporting structure are within the allowable range, so the support scheme is feasible for the project.

\section{Conclusions}

Taking the foundation pit design of Luboyuan Station in the fourth project of Nanjing Metro Line 9 as an example, through the analysis and evaluation of the engineering geological conditions of the project site, this study gives the engineering geological problems that may occur in the process of construction. According to the on-site lithologic characteristics of strata, the hydrogeological conditions, and the structural elements of underground engineering, the design of the foundation pit supporting structure is optimized and analyzed. The conclusions of the study are as follows:

(1) According to the characteristics of large groundwater level, the poor distribution of soil particles, easy-to-occur geological disasters such as piping and quicksand, and the highly complex underground structure, the excavation method of the four-layer 
basin is adopted. This construction method speeds up the construction cycle of the foundation pit and solves the great difficulties brought by the structure to the foundation pit support.

(2) Because the foundation pit's excavation depth is the largest, involving silt layer and fine silt layer, the confined water head is high, and soil's lateral pressure is high. Therefore, the combined supporting structure strengthened by underground diaphragm wall + internal support + triaxial mixing pile floor can effectively control the lateral deformation of soil and groundwater infiltration.

(3) The use of this scheme successfully realized the safe and rapid construction of deep foundation pit projects, avoided large-scale disturbances of the surrounding water and soil, greatly saved energy consumption such as fuel and electricity, and played an important role in protecting the surrounding environment.

\section{Data Availability}

The data used to support the findings of this study are available from the corresponding author upon request.

\section{Conflicts of Interest}

The authors declare that there are no conflicts of interest regarding the publication of this study.

\section{References}

[1] H. Nadrian, H. Mahmoodi, M. H. Taghdisi et al., "Public health impacts of urban traffic jam in sanandaj, Iran: a case study with mixed-method design," Journal of Transport \& Health, vol. 19, Article ID 100923, 2020.

[2] M. F. Geronimo, E. G. H. Martinez, E. D. F. Vazquez, J. J. F. Godoy, and G. F. Anaya, "A multiagent systems with Petri Net approach for simulation of urban traffic networks," Computers, Environment and Urban Systems, vol. 89, Article ID 101662, 2021.

[3] M. Grote, B. Waterson, and F. Rudolph, "The impact of strategic transport policies on future urban traffic management systems," Transport Policy, vol. 110, pp. 402-414, 2021.

[4] Y. X. Wu, H. M. Lyu, S. L. Shen, and A. Zhou, "A threedimensional fluid-solid coupled numerical modeling of the barrier leakage below the excavation surface due to dewatering," Hydrogeology Journal, vol. 28, pp. 1449-1463, 2020.

[5] L. Tian, H. Zhang, and J. Wu, "Data preprocessing based on wavelet and its application in settlement monitoring for urban subway," in Proceedings of the 2010 International Conference on Mechanic Automation and Control Engineering, pp. 4892-4895, Wuhan, China, June 2010.

[6] H. Z. Xu, W. S. Cui, and W. J. Hu, "Deformation behavior of deep excavations of Nanjing subway station in different engineering geological conditions," Journal of Disaster Prevention and Mitigation Engineering, vol. 38, no. 4, pp. 599-607, 2018.

[7] P. Mao, J. Li, L. Xiong et al., "Characterization of urban subway microenvironment exposure - a case of Nanjing in
China," International Journal of Environmental Research and Public Health, vol. 16, no. 4, p. 625, 2019.

[8] P. Zhao, X. Z. Li, J. J. Liu, D. Zhang, and J. Li, "Monitoring and analysis of the subway tunnel wall temperature and surrounding rock/soil heat absorption ratio," Building and Environment, vol. 194, Article ID 107657, 2021.

[9] Z. P. Li, M. K. Li, and Q. H. Huang, "Study of construction technique for the Nanjing subway station under the Nanjing railway station," Chinese Journal of Rock Mechanics and Engineering, vol. 24, pp. 1061-1066, 2005, in Chinese.

[10] H. Xu, P. Sun, and W. Cui, "MSD synthetic system stiffness and deformation prediction of support structure for deep excavation in Nanjing subway," Journal of China University of Mining and Technology, vol. 47, pp. 907-912, 2018.

[11] W. Xu, "Analysis the in and out of the hole region's soil reinforcement technology of the Nanjing subway shield," Open Journal of Transportation Technologies, vol. 2, no. 2, pp. 108-116, 2013.

[12] K. H. Lu and X. Y. Gu, "Space-time evolution of subway vulnerability based on hypergraph space," Mathematical Problems in Engineering, Hindawi, vol. 2020, Article ID 2045838, 10 pages, 2020.

[13] J. Zheng, C. G. She, C. H. Yan, and B. Zhang, "Engineering geological mechanism on deformation of nanjing metro tunnel in operating," Journal of Engineering Geology, vol. 25, no. 1, pp. 199-208, 2017, in Chinese.

[14] Y. X. Wu, S. L. Shen, H. M. Lyu, and A. Zhou, "Analyses of leakage effect of waterproof curtain during excavation dewatering," Journal of Hydrology, vol. 583, Article ID 124582, 2020.

[15] Y. X. Wu, H. M. Lyu, J. Han, and S.-L. Shen, "Dewatering-induced building settlement around a deep excavation in soft deposit in Tianjin, China," Journal of Geotechnical and Geoenvironmental Engineering, vol. 145, no. 5, Article ID 05019003, 2019.

[16] K. Elbaz, S. L. Shen, Y. Tan, and W. C. Cheng, "Investigation into performance of deep excavation in sand covered karst: a case report," Soils and Foundations, vol. 58, no. 4, pp. 1042-1058, 2018.

[17] K. Hermsmeyer, K. Miyagawa, S. T. Kelley et al., "Reactivitybased coronary vasospasm independent of atherosclerosis in rhesus monkeys," Journal of the American College of Cardiology, vol. 29, no. 3, pp. 671-680, 1997.

[18] W. Wang, H. Zhao, J. Deng, X. Zhang, and Y. Zhang, "Study on soil reinforcement param in deep foundation pit of marshland metro station," Heliyon, vol. 5, no. 11, Article ID e02836, 2019.

[19] J. J. Wu, L. M. Peng, J. W. Li et al., "Rapid safety monitoring and analysis of foundation pit construction using unmanned aerial vehicle images," Automation in Construction, vol. 128, Article ID 103706, 2021.

[20] S. H. Ye, Z. F. Zhao, and D. Q. Wang, "Deformation analysis and safety assessment of existing metro tunnels affected by excavation of a foundation pit," Underground Space, vol. 6, no. 4, pp. 421-431, 2021.

[21] X. Y. Cui, M. G. Ye, and Y. Zhuang, "Performance of a foundation pit supported by bored piles and steel struts: a case study," Soils and Foundations, vol. 58, no. 4, pp. 1016-1027, 2018.

[22] J. Zhang, R. Xie, and H. Zhang, "Mechanical response analysis of the buried pipeline due to adjacent foundation pit excavation," Tunnelling and Underground Space Technology, vol. 78, pp. 135-145, 2018. 
[23] H. S. Sun, Y. D. Chen, J. H. Zhang, and T. Kuang, "Analytical investigation of tunnel deformation caused by circular foundation pit excavation," Computers and Geotechnics, vol. 106, pp. 193-198, 2019.

[24] A. Benin, A. Konkov, V. Kavkazskiy, A. Novikov, and N. Vatin, "Evaluation of deformations of foundation pit structures and surrounding buildings during the construction of the second scene of the state academic mariinsky theatre in saint-petersburg considering stage-bystage nature of construction process," Procedia Engineering, vol. 165, pp. 1483-1489, 2016.

[25] H. Y. Zhuang, G. X. Chen, Z. H. Hu, and C. Qi, "Influence of soil liquefaction on the seismic response of a subway station in model tests," Bulletin of Engineering Geology and the Environment, vol. 75, no. 3, pp. 1169-1182, 2016.

[26] C. F. Zuo, D. G. Tang, and D. P. Li, "Research on building deformation caused by the excavation of subway station," in Proceedings of the 2015 International Conference on Architectural, Civil and Hydraulics Engineering, pp. 494-502, Guangzhou, China, November 2015.

[27] Y. You, C. H. Yan, B. T. Xu, S. Liu, and C. Che, "Optimization of dewatering schemes for a deep foundation pit near the Yangtze River, China," Journal of Rock Mechanics and Geotechnical Engineering, vol. 10, no. 3, pp. 555-566, 2018.

[28] C. F. Zeng, G. Zheng, X. F. Zhou, X.-L. Xue, and H.-Z. Zhou, "Behaviours of wall and soil during pre-excavation dewatering under different foundation pit widths," Computers and Geotechnics, vol. 115, Article ID 103169, 2019. 